\title{
Perfusion Index to Assess Hemodynamic Changes and Analgesia with Premedication of Fentanyl versus Nalbuphine during General Anesthesia
}

\author{
Kumkum Gupta', Bhawana Rastogi', Prashant K Gupta ${ }^{2}$, Manoranjan K Bansal ${ }^{3}$, Pavitra Kalra ${ }^{4}$, Sukhreet Kaur ${ }^{4}$ \\ ${ }^{1}$ Professor, Department of Anaesthesiology and Critical care, ${ }^{2}$ Director Professor, Department of Radio diagnosis and Imaging, ${ }^{3}$ Assistant Professor, \\ Department of Anaesthesiology and Critical care, ${ }^{4}$ Resident, Department of Anaesthesiology and Critical care, Subharti Medical College, Partapur Bye \\ Pass Road, Meerut-UP, India
}

\section{Abstract}

Background: The hemodynamic changes are part of stress responses of airway manipulation and surgical pain, which are manifested as tachyarrhythmia and hypertension, and should be ameliorated. This study compared the hemodynamic changes and analgesia with premedication of fentanyl versus nalbuphine during general anesthesia, using perfusion index technique, a non-invasive parameter. Subjects and Methods: After approval, 60 patients of ASA physical status I and II aged between 26 to 56 years of either gender were randomized in two groups of 30 patients each to receive either intravenous fentanyl $2 \mu \mathrm{g} / \mathrm{kg}$ (Group F) or nalbuphine $0.2 \mathrm{mg} / \mathrm{kg}$ (Group N), $5 \mathrm{~min}$ before induction with propofol. Direct laryngoscopy and intubation was facilitated with vecuronium bromide $(0.1 \mathrm{mg} / \mathrm{kg})$. Hemodynamic changes and intraoperative analgesia were recorded at specific time intervals, as primary objectives. Any side effects or complications were noted as secondary outcome. Results: After airway manipulation, the increase in heart rate and systolic blood pressure with decreased perfusion index occurred immediately in patients of both groups which persisted up to 6 to $10 \mathrm{~min}$, thereafter the changes returned back to baseline value with statistically significant difference between both groups. At the time of surgical incision, nalbuphine showed better analgesic effect than fentanyl as assessed by perfusion index. No significant correction between perfusion index and heart rate was observed but there was statistically significant negative correlation between perfusion index and systolic blood pressure. Conclusion: Intravenous fentanyl was more effective for ameliorating the stress response of airway manipulation while nalbuphine was better for intraoperative analgesia as assessed by perfusion index.

Keywords: Perfusion Index; Hemodynamic changes; Fentanyl; Nalbuphine; Pain.

Corresponding Author: Prof (Dr) Kumkum Gupta, 108-109, Chanakyapuri, Shastri Nagar, Meerut-250004 U.P. India

Received: September 2019

Accepted: September 2019

\section{Introduction}

During general anesthesia, airway management and surgical stimulus do affect the autonomic nervous system and increases the circulating plasma catecholamine concentrations, hence predisposing the myocardium to ischemic changes that may be life threatening in vulnerable patients. ${ }^{[1]}$ The magnitude of hemodynamic changes can be ameliorated by opioid analgesics, alpha 2- adrenoreceptors agonist, beta blockers, vasodilators and calcium channel blockers but with their integral shortcomings.

Perfusion index represents a non-invasive method to measure the peripheral perfusion, which is the ratio of the pulsatile blood flow to the non-pulsatile or static blood in peripheral tissue. ${ }^{[2]}$ Perfusion is known to be affected by vasoconstriction and vasodilation, hence may be affected by temperature, stroke volume, tone of sympathetic nervous system, pain, surgical stimulus and anesthetic agents. ${ }^{[3,4]}$ Perfusion index can be used as valuable objective parameters during anesthesia to predict the hemodynamic response to anesthetic drugs, techniques and intraoperative pain along with routine monitoring. ${ }^{[5]}$ The value range of perfusion index is from $0.02 \%$ to $20 \%$. Low perfusion index (PI) suggested peripheral vasoconstriction and pain, while high perfusion index suggested peripheral vasodilation. Haken Taper et al evaluated the perfusion index technique for assessment of pain and concluded that perfusion index can be used for assessment of perioperative pain response to analgesics. $^{[6]}$

Opioid analgesics activate opioid receptors located on primary afferent neurons, resulting in the activation of pain modulating systems. Their activation may either directly decrease neurotransmission or inhibit the release of excitatory neurotransmitters. Morphine, fentanyl and other $\mu$ opioids come under Narcotic Act, hence their availability is a major concern in many hospitals of India, while nalbuphine is easily available and devoid of side effects of nausea, pruritus and respiratory depression.

This observational prospective study was aimed to compare 
the hemodynamic changes and analgesia with premedication of Fentanyl or Nalbuphine during general anesthesia, by using perfusion index technique.

\section{Subjects and Methods}

After approval from Institution Ethical Committee and written informed consent, this observational prospective study was performed on 60 patients of American Society of Anaesthesiologist physical status I and II of both genders, aged between 28 to 58 years with Body Mass Index between 20-25 kg. $\mathrm{m}^{2}$ and scheduled for elective surgeries under general anesthesia.

After pre-anesthetic evaluation, patients with anticipated difficult intubation, known history of cardiopulmonary disease, uncontrolled hypertension, diabetes, hepatic or renal disease, obesity, peripheral vascular disease or taking any pain relieving drugs, were excluded from the study.

All patients were admitted prior to day of surgery and were given Tab Alprazolam $0.5 \mathrm{mg}$ and Tab Ranitidine $150 \mathrm{mg}$, the night before surgery and their nil per oral status for $6 \mathrm{~h}$ was upheld on the day of surgery.

The total 60 patients were randomized into two equal of 30 patients each, according to computer generated random number table and allocation of concealment was ensured with sealed opaque envelop. Patients of Group F were given fentanyl in dose of $2 \mu \mathrm{g} / \mathrm{kg}$, and patients of Group N were given nalbuphine in dose of $0.2 \mathrm{mg} / \mathrm{kg}$. Both study drugs were diluted in $10 \mathrm{~mL}$ isotonic saline and administered intravenously, 5 min before induction.

To avoid bias, study drug was prepared by a resident who was blinded to study protocol and intraoperative parameters were recorded by another resident. Both residents were unaware of group allocation, to make the study double blind. On arrival to operation theatre, baseline vital parameters of heart rate, non- invasive blood pressure, electrocardiogram and peripheral oxygen saturation were initiated. The perfusion index was monitored by using Masimo Radical SET monitor and probe was attached to the middle finger tip of the hand, contralateral to the site of BP monitoring. ${ }^{[7]}$ The probe was wrapped with towel to minimize heat loss and effect of ambient light. An intravenous line was secured and lactate Ringer solution was infused at rate of $4-6 \mathrm{~mL} / \mathrm{kg} / \mathrm{hr}$. The ambient temperature of OT was maintained between $25^{\circ} \mathrm{C}-26^{\circ} \mathrm{C}$.

The patients were premedicated with glycopyrrolate $0.2 \mathrm{mg}$, midazolam $0.02 \mathrm{mg} / \mathrm{kg}$ followed by study drugs. They were given either fentanyl $2 \mu \mathrm{g} / \mathrm{kg}$ or nalbuphine $0.2 \mathrm{mg} / \mathrm{kg}$ or, intravenously, $5 \mathrm{~min}$ before induction, according to randomization schedule in double bind manner. After preoxygenation, anesthesia was induced with propofol $2 \mathrm{mg} / \mathrm{kg}$, followed by vecuronium bromide $0.1 \mathrm{mg} / \mathrm{kg}$ to facilitate direct laryngoscopy and intubation with proper size cuffed endotracheal tube. Anesthesia was maintained with isoflurane (dial concentration of $1 \%$ ), nitrous oxide $(60 \%)$ and oxygen $(40 \%)$. Patients were mechanically ventilated to keep the normocapnia (EtCO2 between 35 to $40 \mathrm{~mm} \mathrm{Hg}$ ). The hemodynamic parameters of heart rate, systemic blood pressure, ECG, perfusion index and peripheral oxygen saturation, were recorded at baseline, after induction and airway management, then at every 5 min interval till end of surgery and post extubation. If intraoperative hypertension (SBP> $20 \%$ of baseline), tachycardia (heart rate $>100 \mathrm{bpm}$ ) and fall in perfusion index occurred, it was managed by increasing the dial concentration of isoflurane and additionally with intravenous paracetamol $(1 \mathrm{Gm})$, if required. Hemodynamic changes occurring during the study period were not treated unless sustained over a time and were compromising the safety of patients. Records of each such patients was kept.

At the end of surgery, isoflurane was discontinued and residual neuromuscular blockade was antagonized by appropriate doses of neostigmine $(0.05 \mathrm{mg} / \mathrm{kg})$ and glycopyrrolate $(0.01 \mathrm{mg} / \mathrm{kg})$. Extubation was performed when respiration became adequate in tidal volume and patient could obey simple commands.

Patients were transferred to post anaesthesia room to monitor the vital parameters. Any hemodynamic changes, respiratory depression, pruritus, nausea and vomiting were noted and treated accordingly.

\section{Sample Size and Statistical Analysis}

After consulting a statistician, sample size was calculated. Approximately 25 patients in each group were required in order to ensure power of $80 \%$ and alpha error of 0.05 with confidence limit of $95 \%$ for detecting clinically meaningful reduction by $20 \%$ in hemodynamic parameters. Assuming a $5 \%$ dropout rate, total 60 patients were incorporated in the study for better validation of results.

After completion of the study, the data collected and expressed as mean and standard deviation, considering the later as best predictor. The results were statistically analyzed by using Stat Graphic Centurion, version 16 (Stat point technologies INC, Warrenton, Virginia). The demographic variable were compared using unpaired ' $t$ ' test and Chi square test. Mean of hemodynamic changes at different time intervals between groups, were compared by one way analysis of variance (ANOVA) and unpaired ' $t$ ' test. Correlation between perfusion index and heart rate as well as systolic blood pressure was calculated using Pearson correlation coefficient. A $\mathrm{p}$ value of less than 0.05 was considered to indicate statistical significance.

\section{Results}

This study compared the clinical efficacy of fentanyl with nalbuphine for hemodynamic changes and analgesia of 60 adult patients of both gender who were screened for potentiation of inclusion criteria of the study. There was no protocol deviation and data of all patients were statistically analyzed.

The demographic profile of age, weight, height, gender and ASA physical status of patients was comparable between both the groups.

Heart rate in patients of both groups were comparable at base line and after premedication. Thereafter, the changes in mean heart rate showed statistically highly significant from baseline at all-time intervals till 10th min. On comparing the two groups, it was observed that increase in heart rate in patients of Group F was $+15.22 \%$ and for patients of Group $\mathrm{N}$ was $+19.76 \%$, from the base values, immediately after 
airway manipulation. Thereafter, changes in heart rate showed decreasing trend towards normal. [Table 2]

On comparing the systolic blood pressure between the groups, there was increase in SBP immediately after airway manipulation in all patients with statistically significant difference between the groups. The maximum increase in SBP for patients of Group F was $+11.09 \%$ and for patients of Group $\mathrm{N}$ was $+18.78 \%$ from the base line. These changes were persisted up to 6 to $10 \mathrm{~min}$, thereafter the systolic blood pressure returned back to normal values with comparable difference between the groups. [Table 3]

The diastolic blood pressure and mean arterial blood pressure were also compared between the groups at different time intervals, which showed a significant rise immediately after airway manipulation in patients of both groups. Thereafter, these values started decreasing steadily in patients of both the groups. [Table $4 \& 5$ ]

Post extubation, there was increase in mean heart rate and systolic blood pressure in patients of both groups with statistically significant difference between the groups.

The perfusion index was compared between the groups at different time intervals. Perfusion index values were decresed from baseline immediately after airway manipulation till $10 \mathrm{~min}$ with statistically significant difference between the groups. Thereafter, PI started increasing steadily at each time interval during intraoperative period.

Correlation between perfusion index and heart rate was statistically insignificant in patients of both groups at the base line, after premedication and induction and post airway stimulation. There was no significant correction between perfusion index and heart rate. Correlation between perfusion index and mean systolic blood pressure was statistically significant in patients of both groups and showed negative correlation, means that as systolic blood pressure was increasing, the perfusion index started decreasing.

Table 1: Demographic data of the study population

\begin{tabular}{|l|l|l|l|}
\hline $\begin{array}{l}\text { Demographic } \\
\text { parameters }\end{array}$ & Group N & Group F & P value \\
\hline Age ( years) & $48.51 \pm 9.2$ & $47.44 \pm 7.6$ & 0.06 \\
\hline Weight $(\mathrm{kg})$ & $59.17 \pm 5.5$ & $60.43 \pm 9.3$ & 0.525 \\
\hline Height $(\mathrm{cm})$ & $154.97 \pm 3.8$ & $155.83 \pm 4.5$ & 0.48 \\
\hline Gender $(\mathrm{M} / \mathrm{F})$ & $18 / 11$ & $19 / 11$ & 0.78 \\
\hline ASA $(\mathrm{I} / \mathrm{II})$ & $21 / 9$ & $22 / 8$ & 0.75 \\
\hline
\end{tabular}

Data are presented in Mean \pm SD or absolute numbers. P value $>0.05$ is statistically insignificant

Table 2: Comparison of mean Heart Rate

\begin{tabular}{|c|c|c|c|}
\hline Time Intervals & Group N & Group F & P value \\
\hline Baseline & $86.82 \pm 4.43$ & $86.69 \pm 3.71$ & 0.902 \\
\hline After study drug & $87.69 \pm 4.73$ & $87.09 \pm 5.10$ & 0.638 \\
\hline After Induction & $83.26 \pm 3.87$ & $78.63 \pm 6.23$ & $0.001 * *$ \\
\hline Immediate post Intubation & $106.11 \pm 3.16$ & $96.60 \pm 3.22$ & $0.001 * *$ \\
\hline $1 \mathrm{~min}$ & $102.63 \pm 2.68$ & $89.60 \pm 2.86$ & $0.001 * *$ \\
\hline $2 \mathrm{~min}$ & $99.91 \pm 3.44$ & $87.47 \pm 3.32$ & $0.001 * *$ \\
\hline $3 \mathrm{~min}$ & $98.91 \pm 3.50$ & $87.17 \pm 2.90$ & $0.001 * *$ \\
\hline $5 \mathrm{~min}$ & $93.97 \pm 3.52$ & $85.66 \pm 0.61$ & $0.001 * *$ \\
\hline $10 \mathrm{~min}$ & $91.34 \pm 4.57$ & $87.17 \pm 3.22$ & 0.256 \\
\hline $15 \mathrm{~min}$ & $86.11 \pm 3.78$ & $82.12 \pm 5.32$ & 0.38 \\
\hline $30 \mathrm{~min}$ & $84.11 \pm 6.37$ & $82.81 \pm 2.34$ & 0.43 \\
\hline $60 \mathrm{~min}$ & $84.61 \pm 4.78$ & $83.12 \pm 3.9$ & 0.68 \\
\hline Post extubation & $101.09 \pm 2.35$ & $92.17 \pm 2.90$ & $0.007^{*}$ \\
\hline
\end{tabular}

Table 3: Comparison of mean Systolic Blood Pressure

\begin{tabular}{|l|l|l|l|}
\hline Time Intervals & Group N & Group F & P Value \\
\hline Baseline & $127.8 \pm 4.36$ & $125.5 \pm 3.15$ & 0.677 \\
\hline After study drug & $122.69 \pm 4.36$ & $121.46 \pm 3.13$ & 0.214 \\
\hline After Induction & $116.23 \pm 3.32$ & $109.68 \pm 4.83$ & $<0.001^{* *}$ \\
\hline $\begin{array}{l}\text { Immediate post } \\
\text { Laryngoscopy and } \\
\text { Intubation }\end{array}$ & $148.43 \pm 4.38$ & $136.43 \pm 3.96$ & $<0.001^{* *}$ \\
\hline $1 \mathrm{~min}$ & & & \\
\hline $2 \mathrm{~min}$ & $148.68 \pm 3.36$ & $137.11 \pm 5.43$ & $<0.001^{* *}$ \\
\hline $3 \mathrm{~min}$ & $139.32 \pm 4.63$ & $135.69 \pm 4.54$ & $<0.001^{* *}$ \\
\hline $5 \mathrm{~min}$ & $136.7 \pm 3.68$ & $132.6 \pm 3.98$ & 0.270 \\
\hline $10 \mathrm{~min}$ & $132.23 \pm 3.20$ & $125.06 \pm 2.75$ & $0.032^{*}$ \\
\hline $15 \mathrm{~min}$ & $128.34 \pm 4.28$ & $118.43 \pm 3.71$ & $0.04^{*}$ \\
\hline $30 \mathrm{~min}$ & $119.1 \pm 4.87$ & $117.10 \pm 4.11$ & 0.38 \\
\hline $60 \mathrm{~min}$ & $116.1 \pm 4.87$ & $115.70 \pm 8.11$ & 0.38 \\
\hline Post extubation & $129.1 \pm 4.87$ & $115.10 \pm 3.41$ & 0.38 \\
\hline $\mathrm{D}$ & $134.3 \pm 4.87$ & $127.10 \pm 4.12$ & 0.38 \\
\hline
\end{tabular}

Data are presented in Mean \pm SD or absolute numbers. ${ }^{*} \mathrm{P}$ value $<0.05$ is statistically significant, ${ }^{* *} \mathrm{P}$ value $<0.001$ is statistically highly significant,

Table 4: Comparison of mean Diastolic Blood Pressure

\begin{tabular}{|l|l|l|l|}
\hline Time Intervals & Group N & Group F & P Value \\
\hline Baseline & $87.62 \pm 7.8$ & $83.42 \pm 8.44$ & 0.57 \\
\hline After study drug & $82.61 \pm 12.49$ & $80.81 \pm 9.66$ & $<0.001^{*}$ \\
\hline After Induction & $76.12 \pm 13.36$ & $74.97 \pm 10.51$ & $<0.001^{*}$ \\
\hline $\begin{array}{l}\text { Immediate post } \\
\text { Intubation }\end{array}$ & $91.45 \pm 14.27$ & $89.84 \pm 12.10$ & $<0.001^{*}$ \\
\hline $1 \mathrm{~min}$ & $89.97 \pm 14.19$ & $88.33 \pm 14.98$ & $<0.001^{*}$ \\
\hline $2 \mathrm{~min}$ & $85.41 \pm 14.57$ & $83.02 \pm 7.96$ & 0.40 \\
\hline $3 \mathrm{~min}$ & $84.10 \pm 12.86$ & $87.31 \pm 12.72$ & 0.92 \\
\hline $5 \mathrm{~min}$ & $82.48 \pm 14.62$ & $79.01 \pm 10.69$ & 0.10 \\
\hline $10 \mathrm{~min}$ & $80.76 \pm 15.02$ & $78.97 \pm 11.64$ & 0.81 \\
\hline $15 \mathrm{~min}$ & $78.71 \pm 15.11$ & $77.80 \pm 11.32$ & 0.77 \\
\hline $30 \mathrm{~min}$ & $78.12 \pm 17.34$ & $77.48 \pm 9.13$ & 0.68 \\
\hline $60 \mathrm{~min}$ & $81.12 \pm 19.13$ & $79.80 \pm 11.37$ & 0.77 \\
\hline Post Extubation & $89.79 \pm 9.81$ & $84.42 \pm 8.44$ & 0.57 \\
\hline
\end{tabular}

Data are presented in Mean \pm SD or absolute numbers. ${ }^{*} \mathrm{P}$ value $<0.05$ is statistically significant. P Value $<0.001$ is statistically highly significant

Table 5: Comparison of average Mean Arterial Pressure

\begin{tabular}{|l|l|l|l|}
\hline Time intervals & Group N & Group F & P Value \\
\hline Baseline & $98.95 \pm 10.4$ & $94.6 \pm 10.74$ & 0.32 \\
\hline After study drug & $94.79 \pm 13.11$ & $90.45 \pm 10.69$ & $0.001^{* *}$ \\
\hline After Induction & $87.69 \pm 14.66$ & $79.95 \pm 11.92$ & $0.001^{* *}$ \\
\hline $\begin{array}{l}\text { Immediate post } \\
\text { Intubation }\end{array}$ & $106.69 \pm 15.06$ & $102.37 \pm 14.32$ & $0.04^{*}$ \\
\hline $1 \mathrm{~min}$ & $105.86 \pm 16.06$ & $100.24 \pm 14.05$ & 0.07 \\
\hline $2 \mathrm{~min}$ & $104.61 \pm 15.11$ & $96.98 \pm 14.26$ & $0.03^{*}$ \\
\hline $3 \mathrm{~min}$ & $101.79 \pm 13.41$ & $92.87 \pm 12.62$ & 0.13 \\
\hline $5 \mathrm{~min}$ & $98.44 \pm 15.57$ & $92.44 \pm 11.65$ & 0.35 \\
\hline $10 \mathrm{~min}$ & $92.74 \pm 16.69$ & $90.1 \pm 12.51$ & 0.26 \\
\hline $15 \mathrm{~min}$ & $93.14 \pm 15.11$ & $89.24 \pm 11.89$ & 0.08 \\
\hline $30 \mathrm{~min}$ & $93.14 \pm 15.11$ & $86.24 \pm 11.89$ & 0.07 \\
\hline $60 \mathrm{~min}$ & $94.14 \pm 15.11$ & $89.24 \pm 11.89$ & 0.18 \\
\hline Post Extubation & $103.98 \pm 10.4$ & $97.6 \pm 10.74$ & 0.06 \\
\hline
\end{tabular}

Data are presented in Mean \pm SD or absolute numbers. ${ }^{*} \mathrm{P}$ value $<0.05$ is statistically significant

\section{Table 6: Changes in Perfusion Index}

Table 6: Changes in Perfusion Index
\begin{tabular}{|l|l|l|l|}
\hline Time Interval & Group N & Group F & P values \\
\hline Baseline & $3.0 \pm 1.0$ & $2.9 \pm 1.3$ & 0.685 \\
\hline After study drug & $3.7 \pm 1.2$ & $3.7 \pm 1.2$ & 1.000 \\
\hline After induction & $3.9 \pm 0.7$ & $3.9 \pm 1.8$ & 0.673 \\
\hline $\begin{array}{l}\text { Immediately post } \\
\text { intubation }\end{array}$ & $1.8 \pm 0.6$ & $2.3 \pm 1.3$ & $0.034^{*}$ \\
\hline $1 \mathrm{~min}$ & $2.2 \pm 1.6$ & $3.1 \pm 1.9$ & $0.001^{*}$ \\
\hline $2 \mathrm{~min}$ & $3.0 \pm 1.7$ & $4.3 \pm 2.0$ & $0.018^{*}$ \\
\hline $3 \mathrm{~min}$ & $3.0 \pm 1.0$ & $4.0 \pm 2.0$ & $0.006^{*}$ \\
\hline $5 \mathrm{~min}$ & $5.0 \pm 1.0$ & $5.0 \pm 1.0$ & 1.000 \\
\hline $10 \mathrm{~min}$ & $5.4 \pm 1.1$ & $6.0 \pm 1.3$ & $0.005^{*}$ \\
\hline $15 \mathrm{~min}$ & $5.9 \pm 1.6$ & $6.0 \pm 1.5$ & 0.874 \\
\hline
\end{tabular}

Data are presented as mean $\pm \mathrm{SD} ; * \mathrm{P}$ value $<0.05$ is statistically significant. 


\section{Discussion}

The major stimuli to intraoperative hemodynamic changes are due to forces exerted by laryngoscope blade on the base of tongue during airway manipulation, leading to upsurge of circulating catecholamine concentrations. These exacerbated hemodynamic response can cause unexpected adverse effects of cardiac dysrhythmias, amplified blood pressure, left ventricular failure or even pulmonary edema which should be ameliorated for better outcome of patients.

Several pharmacological methods are used to ameliorate the magnitude of these hemodynamic responses of airway manipulation and surgical pain. Opioid analgesics and inhalation agents can also attenuate the hemodynamic pressor responses by deepening the anaesthesia. Many studies have shown that fentanyl and nalbuphine were effective for attenuating the hemodynamic pressor responses of airway manipulation and surgical pain. ${ }^{[8]}$

Ko SH et al designed their study to scrutinize the optimal time to administer fentanyl to supress the hemodynamic responses to laryngoscopy and intubation and concluded that the optimal time is 5 min before intubation. ${ }^{[9]}$ Chawda PM et al studied the effect of nalbuphine on hemodynamic pressor responses to tracheal intubation and concluded that nalbuphine in doses of $0.2 \mathrm{mg} / \mathrm{kg}$, should be given 3 to $5 \mathrm{~min}$ before laryngoscopy to prevent the stress response to tracheal intubation. ${ }^{[10]}$ Hence in the present study, nalbuphine and fentanyl were given 5 min before induction.

In present study, after administration of study drugs, mean heart rate in patients of fentanyl group decreased while it increased in patients of nalbuphine group. The mean heart rate after intubation showed significant increase in all patients with statistically significant difference. The heart rate and systolic blood pressure gradually decreased in both the groups.

Khan and Hameedullah conducted a similar study and observed a significant decrease in heart rate response in fentanyl group after induction, tracheal intubation and incision. In their study, the heart rate in nalbuphine group remained significantly high $15 \mathrm{~min}$ post intubation while in present study, the heart rate gradually settled after intubation. ${ }^{[1]}$ Bhandari et al, ${ }^{[12]}$ and Ahsan et al, ${ }^{[13]}$ also support the present study.

Priti M Chawda et al studied the efficacy of nalbuphine to attenuate the increase of heart rate and blood pressure in response to intubation and observed significant rise in heart rate in control group (20.4\%) after intubation at 2 min when compared to nalbuphine $(16.66 \%)$. The heart rate and mean arterial pressure gradually decreased after 3 to $8 \mathrm{~min}$, thus concluded that nalbuphine could attenuate the hemodynamic pressor response to laryngoscopy and intubation. ${ }^{[10]}$ The observations of present study is in consistence with their study.

Perfusion index is an assessment of the pulsatile strength at a specific monitoring site. It is calculated by means of pulse oximetry by expressing the pulsatile signal during arterial flow, as a percentage of non-pulsatile signal. Perfusion index could assess the intraoperative pain during general anesthesia, consequently helps to manage the perioperative pain when patient is unable to communicate their discomfort. ${ }^{[14,15]}$ Various studies are done to evaluate the role of perfusion index as one of the markers of hemodynamic responses of laryngoscopy and surgical pain stimulus. ${ }^{[16]}$

In the present study, the perfusion index was correlated with heart rate and systolic blood pressure at different time intervals in patients of both groups. The study showed no significant correlation with mean heart rate changes in patients of both groups, which indicated that any change in heart rate did not affect the perfusion index. The changes in mean systolic pressure from baseline, did affect the perfusion index value with negative correlation, in patients of both groups.

$\mathrm{H}$ Hager et al measured perfusion index by a pulse oximeter to indicate pain stimuli in anesthetized volunteers. They were induce with propofol $(2 \mathrm{mg} / \mathrm{kg})$ and anesthesia was maintained with varying concentration of Sevoflurane. The standard painful stimuli were provided by two $25 \mathrm{G}$ electric needles inserted into the lower part of anterior thigh bilaterally and a 65-70 mill-ampere, $100 \mathrm{~Hz}$ tetanic electric current was maintained for $10 \mathrm{sec}$. They observed that heart rate and mean arterial blood pressure increased under the influence of painful stimuli and the perfusion index showed a statistically significant decrease during painful stimuli. They concluded that the perfusion index is able to independently indicate a pain stimulus in anesthetized volunteers with different concentrations of Sevoflurane. ${ }^{[17]}$

Kowalezyk et al noted the perfusion index at different time intervals. They stated that perfusion index increased significantly from the start to the end of surgery in all patients of study. They found significant correlation between perfusion index and end tidal desflurane concentration, but there was no correlation between propofol or remifentanil concentration and perfusion index, thus concluded that Sevoflurane and Desflurane increases the perfusion index. ${ }^{[17]}$ Haidry et al compared hemodynamic response to tracheal intubation with Macintosh and McCoy laryngoscopes and concluded that McCoy laryngoscope is safer alternative for intubation. They also stated that perfusion index can replace the conventional parameters to assess hemodynamic stress response during laryngoscopy and intubation since it has good negative correlation with mean arterial pressure. ${ }^{[18]}$

Choudhary et al compared the hemodynamic responses to tracheal intubation with Macintosh versus McCoy laryngoscopes along with perfusion index and concluded that the McCoy laryngoscope elicits lesser hemodynamic response to laryngoscopy and tracheal intubation. They also concluded that perfusion index can also serve as an additional parameter to assess hemodynamic responses as it showed negative correlation with mean arterial pressure. ${ }^{[19]}$ The present study is in consistence with these study.

\section{Conclusion}

Perfusion index could serve as an additional and independent parameters to assess intraoperative hemodynamic changes during airway manipulation and surgical pain in anesthetized patients. Perfusion index has a negative correlation with changes in mean systolic blood pressure, but no correlation with changes in heart rate. Intravenous premedication with fentanyl was more effective for ameliorating the stress 
responses of airway stimulation, while nalbuphine premedication was better for intraoperative analgesia as assessed by perfusion index.

However, larger sample can throw better light before it can be recommended as a routine monitoring parameter and its clinical applicability and importance.

\section{References}

1. Hamunen K, Kontinen V, Hakola E. Talke P, Paloheimo M, Halso E. Effect of pain on autonomic nervous system indices derived from photo plethysmography in healthy volunteers. Br J Anaesth 2001; 108: 83844.

2. Lima AP, Beelen P, Bakker J. Use of peripheral perfusion index derived from the pulse oximetry signal as a non-invasive indicator of perfusion. Crit Care Med 2002; 30: 1210-3.

3. Hakan Tapar, Mustafa Suren, Sarkan Karamen serkan Dogue, Tigba Karamen, Aynur Sahin, Fatih Attiparmak. Evaluation of perfusion index according to Visual Analogue Score in postoperative patients. Saudi Med J 2018; 39: 1006-10.

4. Nishimura T. Nakal A, Shibata M, Mashimo T, Fujino Y. Age related and sex related changes in perfusion index in response to noxious electrical stimulation in healthy subject. J Pain res 2014; 17: 91-7.

5. Llke Kupili, Nur Gozda Kulhan. Can perfusion index be used as an objective tool for pain assessment in labor analgesia? Pak J Med Sci 2018; 24; 1262-6.

6. Hager H, Church S, Mandadi G Pully D, Kurz A. The perfusion index measured by a pulse oximeter indicates pain stimuli in anesthetized volunteers. Anaesthesiology 2004, 101: A514.

7. Goldman JM, Petterson MT, Kopotic RJ, Barker SJ. Masimo Signal extraction pulse oximetry. Journal of Clinical Monitoring and Computing 2000; 16: 475-83.

8. Aqsa Buchh, Kumkum Gupta, Deepak Sharma, Usman Anwar, Mahesh Narayan Pandey, Pavitra Kalra. Comparative evaluation of fentanyl versus nalbuphine for attenuation of hemodynamic changes during airway stimulation. Int J Res Med Sci 2018; 6:623-8.

9. Ko SH, Kim DC, Han YJ, Song HS. Small dose fentanyl: optimal time of injection for blunting the circulatory responses to tracheal intubation. Anaesth Analg 1998; 86: 658-61.

10. Chawda PM, Pareek MK, Mehta KD. Effect of nalbuphine on hemodynamic response to orotracheal intubation. J Anaesth Clin Pharmmacol 2010; 26: 458-60.

11. Khan FA, Hameedullah. Comparison of fentanyl and nalbuphine in TIVA. JPMA 2002; 52: 459.

12. Bhandari R, Rastogi S, Tyagi A, Joshi A, Malik N, Sachdeva A. Attenuation of haemodynamic response to endotracheal intubation with Nalbuphine and Fentanyl: A Comparative Study. J of Evolution of Med and Dent Sci 2015; 4; 11172-81.

13. Ahsan M, Kazmim EH, Akhtar Z et al. Nalbuphine prevents hemodynamic response to endotracheal intubation. Canadian J Anaesth 2006; 53: 261-65.

14. Breink H, Borchgrevink PC, Allen SM, Roeseland CA, Romundslad L Hals EK et al. Assessment of pain. Br J Anaesth 2008; 101: 17-24.

15. Mohmed S, Mohmed N, Rashwant D. Pulse co-oximetry perfusion index as a tool for acute postoperative pain assessment and its correlation to visual analogue pain score. Res Opin Anaesth Intens Care 2015; $2: 62-7$

16. Kowalczy KM, Fizalkowska A, Nestorowicz A. New generation pulse oximetry in assessment of perfusion index during general anaesthesia- a comparison between propofol and desflurane. Anaesthsiol Intensive Ther 2013; 45: 138-44.

17. Hager H, Reddy D, Kurz A. Perfusion Index- A valuable tool to assess changes in peripheral perfusion caused by Sevoflurane? Anaesthesiology 2003; 99: A 593.

18. Haidry MA, Khan FA. Comparison of hemodynamic response to tracheal intubation with Macintosh and McCoy Laryngoscopes. J Anaesthesiology Clinical Pharmacol 2013; 29: 196-9.

19. Choudhary VK, Rastogi B, Singh VP, Ghalot S, Dabass V, Ashraf Sameer. Comparison of hemodynamic responses along with perfusion index to tracheal intubation with Macintosh and McCoy laryngoscopes. Int J Res Med Sci 2018; 6: 1673-81.

Copyright: () the author(s), publisher. Academia Anesthesiologica International is an Official Publication of "Society for Health Care \& Research Development". It is an open-access article distributed under the terms of the Creative Commons Attribution Non-Commercial License, which permits unrestricted non-commercial use, distribution, and reproduction in any medium, provided the original work is properly cited.

How to cite this article: Gupta K, Rastogi B, Gupta PK, Bansal MK, Kalra P, Kaur S. Perfusion Index to Assess Hemodynamic Changes and Analgesia with Premedication of Fentanyl versus Nalbuphine during General Anesthesia. Acad. Anesthesiol. Int. 2019;4(2):255-9.

DOI: dx.doi.org/10.21276/aan.2019.4.2.57

Source of Support: Nil, Conflict of Interest: None declared. 